\title{
The Role of Vocabulary Knowledge in Iranian EFL Students' Reading Comprehension Performance: Breadth or Depth?
}

\author{
Mohammad Taghi Farvardin \\ Department of English, Khorasgan (Isfahan) Branch, Islamic Azad University, Isfahan, Iran \\ Email: a.farvardin@gmail.com \\ Mansoor Koosha \\ Department of English, Khorasgan (Isfahan) Branch, Islamic Azad University, Isfahan, Iran \\ Email: mkoosha@khuisf.ac.ir
}

\begin{abstract}
Two important aspects of vocabulary knowledge, namely breadth and depth, continue to play an indispensable role in vocabulary research. This study aimed to investigate the relationship between vocabulary knowledge and reading comprehension, and to find out which aspect of vocabulary knowledge, breadth or depth, has greater impact on determining reading comprehension performance. Hence, three language tests were used viz. a reading comprehension test, Vocabulary Levels Test revised by Schmitt et al. (2001), and Read's (1998) Word Associates Test. A total of 78 freshmen majoring in TEFL at Islamic Azad University of Najafabad, Iran, participated in the study. The results of the two-tailed Pearson Correlations and multiple regression analyses revealed that 1) test scores on vocabulary breadth, depth of vocabulary knowledge, and reading comprehension were positively correlated 2) vocabulary breadth was a stronger predictor of reading comprehension than depth of vocabulary knowledge and 3) breadth and depth of vocabulary knowledge were closely interrelated $(r=.85, p<.01)$
\end{abstract}

Index Terms — vocabulary breadth, depth of vocabulary knowledge, reading comprehension

\section{INTRODUCTION}

Many researchers believe that vocabulary learning is the most important facet of second-language (L2) learning (Knight, 1994) and "an essential part of mastering a second language" (Schmitt, 2008, p.329). Vocabulary knowledge is indispensable for reading comprehension as well. As Stahl (1983, p.33) proposed, the relationship between reading comprehension and vocabulary knowledge is "one of the best documented relationships in reading research". This relationship between vocabulary and reading comprehension caused a good number of researchers to believe that a reader's vocabulary knowledge can be the best predictor of his understanding of text (Anderson \& Freebody, 1981). However, researchers have differentiated between two facets of vocabulary knowledge, namely breadth and depth (e.g. Bogaards and Laufer, 2004; Read, 2000).

Nation (2001) stated that breadth or size of vocabulary knowledge is the number of words that language learners know. One of the measures widely used to assess the size of vocabulary knowledge is Vocabulary Levels Test (VLT) which has a matching format (Nassaji, 2004). It includes different word-frequency levels ranging from high frequency (2000-word level) to low-frequency words (10,000-word level). This test has become widely used as a vocabulary assessment for L2 learners, and it has been accepted by a number of researchers (e.g., Laufer \& Paribakht, 1998; Qian, $1999,2002)$ as an appropriate measure of vocabulary size.

On the other hand, "depth of vocabulary knowledge refers to how well the language learner knows a word" (Akbarian, 2010, p. 392). Different types of knowledge associated with a word have been recognized such as knowledge of pronunciation, spelling, stylistic features, collocational meanings, antonymy, synonymy, and hyponymy (Nation, 1990; Read, 2000; Richards, 1976). Word Associates Test (WAT) developed by Read (1993, 2000) is a commonly used measure assessing some of these aspects. In this test, according to Read (2004, p. 221), the target word and associates have three basic relationships: "paradigmatic (synonyms), syntagmatic (collocates) and analytic (words representing a key element of the meaning of the target word)". Since these components are important they appear frequently in discussions of vocabulary knowledge (e.g. Nation, 1990, 2001; Qian, 2002; Read, 1993, 2000).

There have been some studies focusing on the relationship between breadth and depth of vocabulary knowledge. Schmitt and Meara (1997) found that correlations between vocabulary breadth and WAT (as a depth test) were relatively high (.61 for receptive knowledge and .62 for productive knowledge). In another study, Nurweni and Read (1999) reported that the correlation between the scores on the tests of breadth and depth of vocabulary knowledge was .62 and the relationship became even stronger $(\mathrm{r}=.81)$ with high-proficiency students. In line with Nurweni and Read (1999), Akbarian (2010) found that VLT (breadth test) and WAT (depth test) had a great deal of common shared 
variance for Iranian ESP graduate students $\left(\mathrm{R}^{2}=.746\right)$. There is also some empirical evidence supporting the impact of vocabulary breadth and depth on reading comprehension. In Laufer's (1992) study, high correlations between vocabulary breadth and reading comprehension were revealed. Laufer (1992) reported that the scores on reading comprehension correlated with both scores on the VLT $(\mathrm{r}=.50)$ and those on the EVST (Eurocentres Vocabulary Size Test) $(r=.75)$. Laufer (1992) concluded that vocabulary breadth is a good indicator of reading comprehension. De Bot et al. (1997) further found that different facets of vocabulary knowledge, such as word morphology and word associations are closely linked to reading comprehension processes.

Qian $(1999,2002)$ investigated the interrelationships among vocabulary breadth, depth of vocabulary knowledge, and reading comprehension across Chinese and Korean readers. Qian (1999) found that scores on vocabulary breadth, depth of vocabulary knowledge, and reading comprehension were highly correlated, and that depth of vocabulary knowledge made a unique contribution to the prediction of learners' reading comprehension performance. Later, Qian (2002) conducted a similar study with 217 participants from 19 different L1 backgrounds and obtained the same results, confirming the importance of the role of both depth and breadth of vocabulary knowledge in reading comprehension. Moreover, Huang (2006) found that breadth and depth of vocabulary knowledge and reading comprehension are positively correlated. Vermeer (2001), on the other hand, argued that too little is known about the relationship between breadth and depth of word knowledge. Vermeer (2001) concluded that there might not be a conceptual distinction between the two dimensions.

Regarding the above-mentioned studies, more empirical evidence on the role of vocabulary knowledge in EFL students' reading comprehension performance is required. The general purpose of this study was to investigate the role of vocabulary knowledge in Iranian EFL university students' reading performance. In the present study, the relationship between vocabulary breadth, depth of vocabulary knowledge, and reading comprehension was investigated.

Research Question

Within the scope of this study, the following questions were addressed:

1) What is the relationship between reading comprehension, vocabulary breadth, and depth of vocabulary knowledge for Iranian EFL university students?

2) Which aspect of vocabulary knowledge, i.e. breadth or depth, is the more powerful predictor of Iranian EFL university students' reading comprehension performance?

\section{METHOD}

\section{A. Participants}

To gather data, 78 freshmen majoring in TEFL at Islamic Azad University of Najafabad, Iran, participated in this study (32 males and 46 females). The participants' age ranged from 18 to 21 . The participants were selected from two intact classes.

\section{B. Instrumentation}

The instruments used in the study included three language tests, viz. a reading comprehension test, Vocabulary Levels Test, and Word Associates Test.

Reading Comprehension Test-The reading comprehension (RC) test items for the present study were drawn from The University of Michigan Examination for the Certificate of Proficiency in English by Briggs et al. (1997). The test contained two reading comprehension passages with the same readability level (12 on the Flesch-Kincaid Grade Level readability scale). Each passage was followed by ten multiple-choice questions. Thus there were 20 multiple-choice questions in total.

Vocabulary Levels Test (VLT)—We used version 2 of VLT, revised and validated by Schmitt et al. (2001). It contained 1000-, 3000-, 5000-, and 10,000-word frequency levels. Each level of the test included 30 items. The maximum possible score was 120 , with one point for each item at the four levels.

Word Associates Test (WAT) - The depth of vocabulary knowledge test in this study was the Word Associates Test (WAT), developed by Read (1998). This test was devised to measure test-takers' depth of receptive English vocabulary knowledge in terms of three elements: synonymy, polysemy, and collocation. The test used in the present study was version 4.0 of the WAT. The split-half reliability of the test in the study by Qian (2002) was 0.89 . WAT contains 40 items, each of which consists of one stimulus word (an adjective), and two boxes, each containing four words. Among the four words in the left box, one to three words can be synonymous to one aspect of, or the whole meaning of, the stimulus word. Also, there can be one to three words that collocate with the stimulus word among the four words in the right box. In scoring, each word correctly chosen was awarded one point. The maximum possible score, therefore, was 160 for the 40 items. The following is an example:

Original

\begin{tabular}{|ll|ll|}
\hline careful closed & first proud & condition mind plan sister \\
\hline
\end{tabular}

\section{Data Collection}


The three tests, the RC, VLT and WAT, were administered to each participant in a single testing session. To eliminate the possibility of an order effect, the tests were administered in a counterbalanced order. That is, each participant took the three tests in one of six different orders. The orders are listed as follows:

1. RC- VLT- WAT

2. RC- WAT- VLT

3. VLT- RC- WAT

4. VLT - WAT- RC

5. WAT- RC- VLT

6. WAT- VLT- RC

\section{Data Analysis}

To answer the research questions, quantitative data (i.e., scores of the three language tests) was used (1) to reveal the relationship between reading comprehension, vocabulary breadth, and depth of vocabulary knowledge, and (2) to determine the more powerful predictor of reading comprehension from scores on vocabulary breadth and depth of vocabulary knowledge. Two-tailed Pearson correlation and multiple regression analysis were the main statistical techniques chosen to meet the research purpose of the study. To explore the intercorrelations among the RC, VLT, and WAT, two-tailed Pearson correlations were calculated. In the multiple regression analysis, scores on the VLT and WAT were used as the predictors or independent variables and score on the RC as dependent variable, in order to determine the stronger predictor of reading comprehension. SPSS 17.0 was used for analysing the data.

\section{RESULTS}

To answer the research questions, correlation and multiple regression analyses were used. The procedure included three phases.

Phase 1: Descriptive statistics and test reliability

In the first phase of the analysis, descriptive statistics and reliability coefficients of the participants' scores on the three tests (RC, VLT, and WAT) were computed. The results of the descriptive and reliability analyses are shown in Table 1, which lists the score range, mean, standard deviation, and reliability (Cronbach Alpha) of the three tests. To make the three tests more comparable, the percentages for the score ranges and mean scores are inserted alongside in parentheses.

TABLE 1.

DESCRIPTIVE STATISTICS AND RELIABILITY OF THE RC, VLT, AND WAT (N=78)

\begin{tabular}{cccccc}
\hline Test & Maximum Score & Score Range & Mean Score & $\begin{array}{c}\text { Standard } \\
\text { Deviation }\end{array}$ & $\begin{array}{c}\text { Reliability } \\
\text { (Cronbach Alpha) }\end{array}$ \\
\hline RC & 19 & $8(40 \%)-19(95 \%)$ & $13.2(66 \%)$ & 3.23 & .72 \\
\hline VLT & 108 & $54(45 \%)-108(90 \%)$ & $87.63(73 \%)$ & 8.78 & .89 \\
\hline WAT & 134 & $96(60 \%)-134(84 \%)$ & $112(70 \%)$ & 11.14 & .81 \\
\hline
\end{tabular}

Phase 2: Correlations

To answer the first question, the correlations between the scores on the RC, VLT, and WAT were determined. A twotailed Pearson correlation analysis was conducted. The results are displayed in Table 2. The intercorrelations among the three tests are all both positive and statistically significant. The correlation between the RC and VLT $(r=.78)$ is higher than that between the RC and WAT $(r=.72)$, and the correlation between the VLT and WAT is the highest $(r=.85)$.

TABLE 2.

TWO-TAILED PEARSON CORRELATIONS BETWEEN SCORES ON THE RC, VLT, AND WAT (N=78)

\begin{tabular}{cccc}
\hline Test & RC & VLT & WAT \\
\hline RC & - & $.78^{* *}$ & $.72^{* *}$ \\
\hline VLT & $.78^{* *}$ & - & $.85^{* *}$ \\
\hline WAT & $.72^{* *}$ & $.85^{* *}$ & - \\
\hline \multicolumn{5}{c}{$*^{*} \mathrm{p}<.01$}
\end{tabular}

Phase 3: Multiple regression analyses

To answer the second question, multiple regression analyses were conducted. To determine the more powerful predictor of reading comprehension, scores on VLT and WAT were taken as the predictor (or independent) variables and score on the RC as the dependent variable.. Table 2 indicates that the predictor variable VLT has a stronger correlation with the dependent variable $\mathrm{RC}(\mathrm{r}=.78, \mathrm{p}<.01)$ than the predictor variable WAT $(\mathrm{r}=.72, \mathrm{p}<.01)$. Therefore, the predictor variable VLT was chosen to be entered into the regression equation first. The first section of Table 3 (labeled A) presents the results where VLT was entered first into the equation, followed by WAT. 
TABLE 3

MultiPle REgRESSION ANALYSES USING SCORE ON THE RC AS DEPENDENT VARIABLE AND SCORES ON THE VLT AND WAT AS PREDICTOR VARIABLES $(\mathrm{N}=78)$

\begin{tabular}{lllll}
\hline Step & $\begin{array}{l}\text { Predictor variable(s) } \\
\text { involved }\end{array}$ & $\mathrm{R}^{2}$ & Adjusted $\mathrm{R}^{2}$ & $\mathrm{R}^{2}$ Change \\
\hline $\mathbf{A})$ & & $.615^{*}$ & $.523^{*}$ & \\
1 & VLT & .652 & .535 & .037 \\
2 & VLT, WAT & & & \\
\hline B) & & $.482^{*}$ & $.448^{*}$ & .170 \\
1 & WAT & .652 & .535 & \\
2 & WAT, VLT & $* \mathrm{p}<.05$ &
\end{tabular}

As Table 3 shows, when VLT was entered into the equation first, the R2 value at this step was .615 and the adjusted $\mathrm{R} 2$ value .523 . VLT alone accounted for $50.0 \%(\mathrm{R} 2=.615)$ of the variance in the dependent variable RC. Also, VLT, as a predictor, explained a significant amount of the RC variability. As VLT remained in the equation, WAT was then added at the second step. At this point, the R2 value changed to .652 and the adjusted R2 value changed to .535 . VLT and WAT jointly accounted for $65.2 \%(\mathrm{R} 2=.652)$ of the variance in RC but the WAT measure did not predict significantly over and above the VLT measure $(\mathrm{R} 2$ change $=.037)$. The entry of WAT at the second step contributed only an additional $3.7 \%$ (R2 change $=.037$ ) of the variance in RC. In other words, WAT did not explain a significant proportion of RC variance after controlling for the effect of VLT.

To further investigate the unique contribution made by the WAT measure, another regression analysis was carried out by reversing the order of entry for the predictor variables into the equation. The second section of Table 3 (labeled B) shows the results where VLT was entered after WAT. When WAT was entered into the equation at the first step, the R2 value was .482, indicating that WAT alone explained $48.2 \%$ of the variance in RC. Next, when VLT was added to the equation at the second step, the R2 value increased by $.170(\mathrm{R} 2$ change $=.170)$ to .652 . That is, VLT explained an additional $17 \%$ of the variance in RC above the $48.2 \%$ variance already accounted for by WAT. However, the VLT measure did not predict significantly over and above the WAT measure.

\section{DISCUSSION}

This study aimed to investigate the role of vocabulary knowledge in Iranian EFL university students' reading performance. In the present study, the relationship between vocabulary breadth, depth of vocabulary knowledge, and reading comprehension was investigated.

To explore the intercorrelations among the RC, VLT, and WAT, two-tailed Pearson correlations were calculated. The result showed that the scores on the three language tests positively correlated with one another. The correlation between the RC and VLT ( $r=.78)$ was higher than that between the RC and WAT $(r=.72)$. This indicates that the score on vocabulary breadth was more strongly correlated with the test-taker's reading comprehension performance than the score on their depth of vocabulary knowledge. In other words, vocabulary breadth appeared to be in a stronger relationship with reading comprehension than vocabulary depth. Furthermore, among the three tests, the highest correlation was between the scores on the VLT and WAT $(r=.85)$. It shows that the two variables, vocabulary breadth and depth of vocabulary knowledge, are themselves highly correlated. The strong relationship between breadth and depth of vocabulary knowledge is found to be consistent with the results of previous studies (Akbarian, 2010, Huang, 2006; Nurweni and Read, 1999; Qian, 2002). The high correlation shown in the study $(\mathrm{r}=.85)$ leads us to suppose that the breadth and depth of vocabulary knowledge is closely interrelated and could be even interdependent. It can be inferred that one would not normally have vocabulary size knowledge without acquiring some depth knowledge. In addition, the overlapping concept of the two measures may have an impact on the results. Although WAT explores more and deeper facets of vocabulary knowledge, that is the synonymy and polysemy, WAT actually tries to measure the basic word meaning that the VLT requires, and the knowledge of collocation is more or less affected by knowledge of individual word meaning.

In the multiple regression analysis, the results suggested that both VLT and WAT contributed significantly to the prediction of RC. The analysis yielded results that the VLT measure alone accounted significantly for $61.5 \%$ of the variance in RC, while only $48.2 \%$ of the variance in $\mathrm{RC}$ was explained by the WAT measure. In other words, it turned out that vocabulary breadth is a more powerful predictor of reading comprehension performance than depth of vocabulary knowledge. The finding is in line with that of Huang (2006). The finding that the WAT made small but independent further contribution is similar to Qian's $(1999,2002)$ finding, apart from the further contribution the WAT measure made in Qian's studies.

\section{CONCLUSION}

The results of the study revealed that both vocabulary breadth and depth correlated positively with Iranian EFL students' reading comprehension performance. Although, in this study, vocabulary breadth appeared to be a stronger predictor of reading comprehension than depth of vocabulary knowledge, it was found that both aspects play very 
important roles in reading comprehension. In other words, the results suggested that both breadth and depth are useful predictors of reading comprehension performance and even a combination of the two associates better with reading comprehension than either one alone. The findings may be applied to teaching new vocabulary and developing materials for Iranian EFL students.

Limitations of the Study and Suggestions for Future Research

There are many external factors that should be further controlled in future research. The increase of the number of participants in future research may strengthen the reliability of the results. Investigating other Farsi-speaking EFL learners from different language proficiency levels should be considered in the future research. Moreover, the vocabulary tests used in the study measured only the participants' receptive knowledge. Further, the participants' productive vocabulary knowledge was not tested, and it may make the results of the study incomplete to some degree. Assessing productive vocabulary knowledge should be included in future research. To delve more into the depth of the learners' lexical knowledge, we need in-depth vocabulary measures. Although the majority of vocabulary tests concern vocabulary breadth, there are hitherto few test formats assessing depth of vocabulary knowledge efficiently. In other words, there is a gap between research and assessment in vocabulary studies. Hence, developing well-designed measures of depth of vocabulary knowledge is much needed. Also, it is hoped that more studies pursue other aspects of vocabulary breadth versus depth in the future.

\section{REFERENCES}

[1] Akbarian, I. (2010). The relationship between vocabulary size and depth for ESP/EAP learners. System, 38, $391-401$.

[2] Anderson R.C. \& P. Freebody, (1981). Vocabulary knowledge. In J. T. Guthrie (Ed.), Comprehension and Teaching: Research Perspectives. Newark, DE: International Reading Association.

[3] Bogaards, P., Laufer, B. (2004). Vocabulary in a Second Language. Amsterdam: John Benjamins Publishing Company.

[4] De Bot, K., Paribakht, T. S., \& Wesche, M. B. (1997). Toward a lexical processing model for the study of second language vocabulary acquisition. Studies in Second Language Acquisition, 19, 309-329.

[5] Huang, H. F. (2006). Breadth and Depth of Vocabulary Knowledge: Which Really Matters in the Academic Reading Performance of Chinese University Students? Unpublished Master's Thesis, McGill University, Montreal, Canada.

[6] Knight, S. (1994). Dictionary: The tool of last resort in foreign language reading? A new perspective. The Modern Language Journal, 78, 285-299.

[7] Laufer, B. (1992). How much lexis is necessary for reading comprehension? In P. Arnaud, \& H. Bejoint (Eds.), Vocabulary and applied linguistics, (pp. 126-132). London: Macmillan.

[8] Laufer, B., \& Paribakht, T. S. (1998). The relationship between passive and active vocabularies: Effects of language learning context. Language Learning, 48, 365-391.

[9] Nassaji, H. (2004). The relationship between depth of vocabulary knowledge and L2 learners' lexical inferencing strategy use and success. Canadian Modern Language Review, 61, 107-134.

[10] Nation, I. S. P. (1990). Teaching and learning vocabulary. New York: Newbury House.

[11] Nation, I. S. P. (2001). Learning vocabulary in another language. Cambridge, England: Cambridge University Press.

[12] Nurweni, A., \& Read, J. (1999). The English vocabulary knowledge of Indonesian University students. English for Specific Purposes, 18, 161-175.

[13] Qian, D. D. (1999). Assessing the roles of depth and breadth of vocabulary knowledge in reading comprehension. Canadian Modern Language Review, 56, 282-307.

[14] Qian, D. D. (2002). Investigating the relationship between vocabulary knowledge and academic reading comprehension: an assessment perspective. Language Learning, 52, 513-536.

[15] Read, J. (1993). The development of a new measure of L2 vocabulary knowledge. Language Testing, 10, 355-371.

[16] Read, J. (1998). Validating a test to measure depth of vocabulary knowledge. In A. Kunnan (ed.), Validation in language assessment (pp. 41-60). Mahwah, NJ: Lawrence Erlbaum.

[17] Read, J. (2000). Assessing vocabulary. Cambridge, England: Cambridge University Press.

[18] Read, J., (2004). Plumbing the depths: how should the construct of vocabulary knowledge be defined. In: Bogaards, P., Laufer, B. (Eds.), Vocabulary in a Second Language, (pp. 209- 227). Amsterdam: John Benjamins Publishing Company.

[19] Richards, J. C. (1976). The role of vocabulary teaching. TESOL Quarterly, 10, 77-89.

[20] Schmitt, N., \& Meara, P. (1997). Researching vocabulary through a word knowledge framework: word associations and verbal suffixes. Studies in Second Language Acquisition, 19, 17-36.

[21] Schmitt, N., (2008). Review article: Instructed second language vocabulary learning. Language Teaching Research, 12, 329363.

[22] Schmitt, N., Schmitt, D., Clapham, C., (2001). Developing and exploring the behaviour of two new versions of the vocabulary levels test. Language Testing, 18, 55- 88.

[23] Stahl, S.A. (1983). Differential word knowledge and reading comprehension. Journal of Reading Behavior, 15, 33-50.

[24] Vermeer, A., (2001). Breadth and depth of vocabulary in relation to L1/L2 acquisition and frequency of input. Applied Psycholinguistics, 22, 217- 234. 


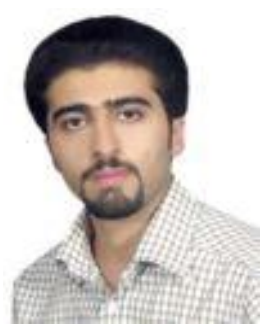

Mohammad Taghi Farvardin is currently a $\mathrm{PhD}$ candidate in Teaching English as a Foreign Language in Islamic Azad University, Khorasgan (Isfahan) Branch. He has published papers in international journals and presented papers in national conferences. His areas of interest include vocabulary acquisition, EFL reading and writing, and language assessment.

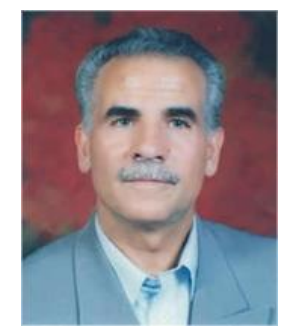

Mansoor Koosha is an associate professor of applied linguistics. He received his B.A. in English Language and Literature from Isfahan University, Iran, in 1961. He earned his M.A. in Teaching English as a Foreign Language (TEFL) from American University of Beirut, Lebanon, in 1970. Later, he did his Ph.D. studies in English Education in University of Colorado, U.S.A., 1980. He is currently an associate professor at Islamic Azad University, Khorasgan (Isfahan) Branch, Iran. He has published several ESP textbooks for EFL students in Iran, and has also been the author of several articles in Iran and abroad. His research interests include materials development, L2 acquisition, EFL reading, translation studies, and ESP. 